\title{
Laparoscopic Treatment of Giant Abdominal Lymphangioma in a Child
}

\author{
Giulia Giannotti, MD, Giovanni Boroni, MD, Luca Giacomo Tonegatti, MD, Susanna Milianti, MD, \\ Fabio Torri, MD, Marco Schiavo Lena, MD, Daniele Alberti, MD \\ Department of Pediatric Surgery, University of Brescia, Italy (Drs. Giannotti, Boroni, Tonegatti, Milianti, Torri, Lena, Alberti). \\ Department of Pathological Anatomy, University of Brescia, Italy (Dr. Marco).
}

\begin{abstract}
Giant cystic lymphangioma (GCL) is a rare benign cystic tumor. The gold standard treatment of abdominal GCL is surgical excision. Only few series of pediatric patients managed with mini-invasive surgery are reported. We describe a case of a 2-year-old girl with a GCL who was treated with laparoscopic excision with a good outcome. She was admitted to our hospital because of acute abdominal pain associated with high temperature. At physical examination, the abdomen was distended and tender. An x-ray film and ultrasonography with Doppler of the abdomen shows the presence of large amount of corpusculated fluid into the peritoneal cavity. Computed tomography showed a very large, septated, cystic abdominopelvic lesion, with the small bowel and colon displaced in the central abdomen. At laparoscopy, GCL arising from the great omentum was identified and completely removed. Histological examination confirmed the diagnosis. At 2-year follow-up, the child is doing well.
\end{abstract}

Key Words: Laparoscopy, Lymphangioma, Pediatric age.

Citation Giannotti G, Boroni G, Tonegatti LG, Milianti S, Torri F, Schiavo Lena M, Alberti D. Laparoscopic treatment of giant abdominal lymphangioma in a child CRSLS e2014.00026. DOI: 10.4293/CRSLS.2014.00026.

Copyright $\odot 2014$ SLS This is an open-access article distributed under the terms of the Creative Commons Attribution-Noncommercial-ShareAlike 3.0 Unported license, which permits unrestricted noncommercial use, distribution, and reproduction in any medium, provided the original author and source are credited.

Address correspondence to: Giulia Giannotti, MD, Department of Pediatric Surgery, University of Brescia, Italy. Phone: +39 3392020215 E-mail: giannottigiu@gmail.com.

\section{INTRODUCTION}

Giant cystic lymphangioma (GCL) is a rare benign cystic tumor, often seen in pediatric patients; $60 \%$ are present at birth, and 90\% present in the first 5 years of life. This malformation can be found at all anatomic locations. Twenty percent of the cases have an abdominal location, and these can be seen as mesenteric or omental cysts. GCL incidence has been reported from 1:20 000 to 1:100 000 hospital admission. ${ }^{1}$ The standard treatment is a laparotomy and complete excision of the lesion. ${ }^{2}$ The first laparoscopic excision of a mesenteric cyst was reported by Mackenzie et $\mathrm{al}^{3}$ in 1993. Since then laparoscopy has been used for treatment of abdominal lymphangioma, but the number of reports of abdominal lymphangioma in the pediatric age is limited. We describe a case of a 2-year-old girl with a GCL who was treated with laparoscopic excision with a good outcome.

\section{CASE REPORT}

A 2-year-old female patient was admitted to our hospital because of acute abdominal pain associated with high temperature $\left(39^{\circ} \mathrm{C}\right)$. The patient had Down syndrome and heart surgery in her medical history. At physical examination, the abdomen was distended and tender; no other significant findings were noted. Laboratory data showed leukocytosis of $28800 / \mathrm{mm}^{3}$ and high C-reactive protein value of 184 (normal value: $<5 \mathrm{mg} / \mathrm{l}$ ). Kidneys and liver function tests were in the normal range as was the total protein level. An x-ray film of the abdomen showed displaced bowel loops. Abdominal ultrasonography with Doppler confirmed the presence of large amount of fluid in the peritoneal cavity with normal portal vein patency and flow. Computed tomography showed a very large, septated, cystic abdominopelvic lesion, with the small bowel and colon displaced in the central abdomen. Liver, spleen, kidneys, adrenal glands, gallbladder, and pancreas were normal (Figure 1).

Broad spectrum antibiotics (gentamicin and piperacillin) were administered, and after 1 week we performed a laparoscopic resection of the whole cyst. Three trocars were placed in the umbilicus $(10 \mathrm{~mm})$, suprapubic region 


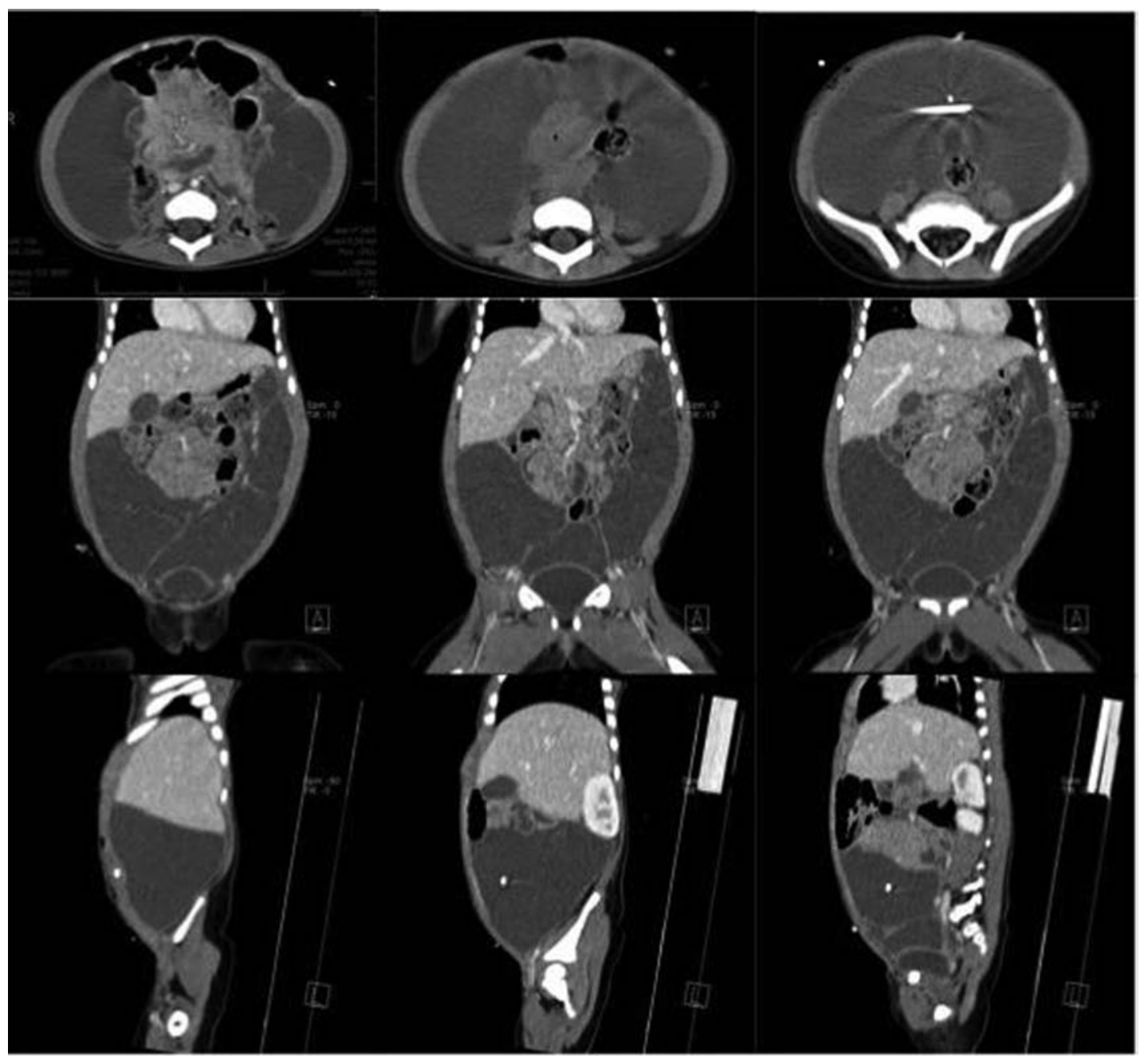

Figure 1. Computed tomography showed a septated cystic abdominopelvic lesion, with compressive effect on the abdominal organs, especially the small bowel and colon are displaced in the central abdominal quadrants.

( $5 \mathrm{~mm})$, and right iliac fossa $(3 \mathrm{~mm})$. A $10 \mathrm{~mm} \mathrm{Hg}$ pneumoperitoneum (flow: $1 \mathrm{~L} / \mathrm{min}$ ) was created. On entering the peritoneal cavity, a giant yellowish cystic tumor was found. The lesion appeared strongly adherent to the anterior abdominal wall, and a monopolar low-current electrocautery hook was used to detach it from the abdominal wall. The tumor was arising from the greater omentum. After evacuation of the intracystic fluid, the tumor was resected with the aid of LigaSure device (Covidien, Mansfield, Massachusetts). Colon, small intestine, and other abdominal organs were normal. The lesion was then removed through the umbilical wound. Macroscopically, the tumor contained some septa and yellowish, transparent fluid.

Histological examination confirmed the diagnosis of GCL. The tumor was composed of cystically dilated lymphatic spaces, which were partially invested by a layer of smooth muscle and were associated to occasional lymphoid aggregates. The lymphatic spaces contained clear fluid or they were empty. The lymphatic endothelial cells lining the cystic spaces were generally attenuated without any cytological atypism. The immunohistochemistry showed that the endothelial cells lining the dilated lymphatic spaces were D2-40 and CD34 positive, and all were negative for keratin. The fibrous septa also contained aggregates of foamy macrophages in some areas (Figure 2 ).

The postoperative course was uneventful, and the child was discharged home 4 days after surgery. At 2-year follow-up, the child is well without any clinical and ultrasonographic signs of recurrence. 


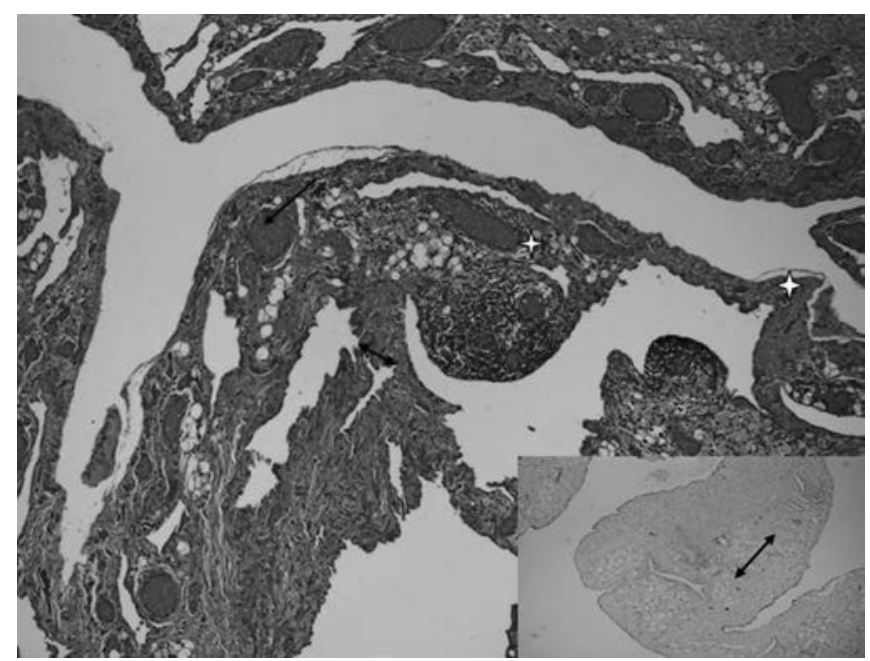

Figure 2. Proliferation of lymphatic channels (arrow) within fibrous septa containing vascular channels, adipocytes, histiocytes, and lymphoid aggregates (star). (Hematoxylin and eosin, $20 \times$ ). Inset particularly shows D2-40 positivity.

\section{DISCUSSION}

GCLs are uncommon benign tumors derived from the lymphatic vessels. Their etiology is unknown and might be associated with developmental anomalies causing a failure of communication between lymphatic vessels. ${ }^{4}$ The clinical presentation is various, ranging from an asymptomatic incidentally discovered lesion to symptoms of acute abdomen with vomiting, abdominal distension, peritonitis, palpable abdominal mass, or ascites. ${ }^{3}$ The most frequent complications of the lesions, such as bleeding, infection, or bowel obstruction, can be causes of emergency admission and operation. In our case, the patient had signs of systemic infection with fever, leukocytosis, and increased C-reactive protein.

The diagnosis is highly suspected on imaging studies, but definitive diagnosis is always based on the histological findings. ${ }^{5}$ In most cases, ultrasound is the procedure of choice but computed tomography or magnetic resonance imaging scans are essential for planning the surgical procedure, and a scan can better define the relations of the cyst with the surrounding structure, especially the abdominal major blood vessels. ${ }^{1,6}$

When the diagnosis is uncertain, celioscopy can help through a biopsy, and it can be used to plan a correct excision when the origin of the lesion is not clear, as in our case. The laparoscopic approach allowed us to define the origin of the cyst and to perform a complete excision without any residual. The uncertain origin of the tumor was the reason we did not think about a percutaneous sclerosing therapy.

GCL can be treated via a single port, in cases of omental cysts and mobile simple mesenteric cysts (types I and II according to Losanoff et al). ${ }^{4}$ Tran and Nguyen ${ }^{1}$ recommend beginning the laparoscopy with 1 umbilical trocar with an operative camera (10-mm camera with an engrafted 5-mm working cannel), and they demonstrate that, in many cases, the wall of the cyst can be grasped and delivered out through the umbilical incision. The cyst is then excised (with or without bowel resection) extracorporally. In our case, due to a previous episode of infection, the lymphangioma was strongly and extensively adherent to the abdominal wall, and we considered its resection with only 1 trocar to be impossible. Therefore we decided to remove the lesion intra-abdominally using 2 more ports.

As the laparoscopic approach is associated with minimal parietal scars, reduced postoperative ileus, and decreased risk of intestinal adhesion, it is our favored approach, especially if the cysts are infected or have bleeding complication, as in our case. Furthermore we can avoid large laparotomy when the cyst is huge. The size of the lesion does not matter because the cystic fluid can be aspirated to increase the working space. ${ }^{1,6}$

Even if the number of reports on laparoscopic management of abdominal cystic lymphangioma in children is quite limited, and most of them reported isolated cases or small series, the literature shows that this procedure is safe with no perioperative complications or mortality. ${ }^{6-8}$ The recurrence rate does not appear to be related to the type of surgical approach. Tran and Nguyen ${ }^{1}$ with the largest series of pediatric patients treated by laparoscopy, reported only 1 recurrence of a complex mesenteric cyst (2.1\%), whereas Steyaert et al ${ }^{9}$ reported a recurrence rate of $9.5 \%$ after open surgery.

Because of the advantages of minimally invasive surgery, even if there are few series of pediatric patients in the literature, we recommend that laparoscopy should be indicated for most abdominal lymphatic cysts in children. According to our limited experience, there is almost no difficulty in performing laparoscopic resection of omental cyst. In cases of complex cysts involving major blood vessels or intestinal loop, the laparoscopic procedure can be difficult and an intestinal resection may be necessary. However the use of previous laparoscopy allows the performance of a short, better targeted laparotomy on the level at the invaded intestinal area, thereby avoiding a major laparotomy. ${ }^{6}$ 


\section{CONCLUSIONS}

In summary, laparoscopy can be an important tool in the management of abdominal cystic lymphangioma. It can help with the diagnosis and it allows total resection either for localized or very large lesions, as in our case. Laparoscopy is safe, feasible, and effective, and we suggest it should be the treatment of choice for most cases of abdominal cystic lymphangioma in children.

\section{References:}

1. Trans NS, Nguyen TL. Laparoscopic management of abdominal lymphatic cyst in children. J Laparoendosc Adv Surg Tech A. 2012;22(5):505-507.

2. Luo CC, Huang CS, Chao HC, Chu SM, Hsueh C. Intraabdominal cystic lymphangiomas in infancy and childhood. Chang Gung Med J. 2004;27(7):509-514.

3. Mackenzie DJ, Shapiro SJ, Gordon LA, Ress R. Laparoscopic excision of a mesenteric cyst. J Laparoendosc Surg. 1993;3(3): 295-299.
4. Losanoff JE, Richman BW, El-Sherif A, Rider KD, Jones JW. Mesenteric cystic lymphangioma. J Am Coll Surg. 2003;196(4): 598-603.

5. Rami M, Mahmoudi A, El Madidi A, et al. Giant cystic lymphangioma of the mesentery: varied clinical presentation of 3 cases. Pan Afr Med J. 2012;12:7.

6. De Lagausie P, Bonnard A, Berrebi D, et al. Abdominal lymphangiomas in children: interest of the laparoscopic approach. Surg Endosc. 2007;21(7):1153-1157.

7. Shamiyeh A, Rieger R, Schrenk P, Wayand W. Role of laparoscopic surgery in treatment of mesenteric cysts. Surg Endosc. 1999;13(9):937-939.

8. Wildhaber BE, Chardot C, Le Coultre C, Genin B. Total laparoscopic excision of retroperitoneal cystic lymphangioma. $J$ Laparoendosc Adv Surg Tech A. 2006;16(5):530-533.

9. Steyaert H, Guitard J, Moscovici J, Juricic M, Vaysse P, Juskiewenski S. Abdominal cystic lymphangioma in children: benign lesions that can have a proliferative course. I Pediatr Surg. 1996;31(5):677-680. 